\title{
NBIC-Convergence as a Paradigm Platform of Sustainable Development
}

\author{
Elena Dotsenko ${ }^{1, *}$ \\ ${ }^{1}$ Plekhanov Russian University of Economics, Department of Political Economy and History of \\ Economic Science, 117997, Moscow, 36 Stremyanny lane, Russia
}

\begin{abstract}
Today, the fastest rates of scientific and technological development are typical for the spheres of nano-systems and materials industry, information and communication systems, as well as spheres of direct human impact on environment - power industry, urbanization, and industrial infrastructure. Accelerate replacement of a human by machines and robots, the construction of megacities; the transportation of huge volumes of environmentally hazardous goods takes place against the background of intensive generation of knowledge, the transition of the results of fundamental research into specific production technologies. In this process, on the one hand, a fundamentally new format for technological restructuring of the world economy is being developed. On the other hand, a new platform for human-environment interaction is being formed, where both positive and negative environmental impacts will be determined by unstudied factors in the near future. The reason for this is in the forthcoming replacement of the technologies that are familiar to us, although dynamically developing, by fundamentally new - convergent. Entering the front line of technological development - NBIC-convergence requires a new paradigm of sustainable development.
\end{abstract}

\section{Introduction}

The rapid development of bio- and nano-technologies is going faster than computer technology. The development of science, technology and the actual process of cognition, as a higher level of human intellectual development, were in a state of relative balance and harmony. However, with the rapid development of high technologies, the process of cognition cannot keep the evolutionary principles of development. The giant speed of the emergence of fundamentally new information, its scale and modification justifies the creation of a new format and principles for responding to the results of scientific and experimental activities. The procedure of analytical generalization and operational decision-making on the reduction of dangerous consequences of risks, the achievement of the desired effectiveness of symbiosis of science and technology, should be presented by electronic data processing complexes in the format of information technology and analytical standards.

\footnotetext{
* Corresponding author: ktyf110372@rambler.ru
} 
This trend of development of scientific activity is realized in a relatively young sphere of social development - cognitive sciences and technologies. It is these technologies that will determine the form, content and intensity of human impact on the environment in the near future. And being the main engine of not only scientific and technical, but also economic, social progress, NBIC-convergent technologies will become a key for the sustainable development of the mankind in the 21 st century.

\section{Materials and methods}

In the dialectic of cognition, the development of cognitive sciences represents a new stage in the development of meta-sciences, their consolidation into the system of a scientific worldview, taking into account a fundamentally new scientific and technological basis and the level of innovation development. It has a special importance for mining regions where sustainable development is constrained by technological [1-2], economic [3-6] and environmental [7-9] challenges. The development of cognitive sciences and technologies will be carried out at an accelerated pace and cover practically the entire spectrum of social and natural science disciplines, fundamental and applied research and development [11-13].

Biotechnologies and nanotechnologies, information and communication technologies and cognitive sciences and technologies closely interact with each other and in their totality form a system of converged NBIC technologies that predetermine the main directions of the progress of science and technology at the present stage of social development.

The effectiveness of such convergence is justified by the realities of the synergetic effect of the system development of basic technologies and science. Converged NBICtechnologies are characterized by many distinctive features. Here, first of all, there are basically new functional qualitative features:

- science is the dominant factor in the development of basic and converged technologies;

- the methodology of science, remaining the basis of knowledge, in the conditions of the development of cognitive sciences and the development of NBIC-technologies passes to a higher level of its development - the technology of cognition. As a result, the interpenetration of sciences and the integration of scientific knowledge into the overall system of the scientific worldview take place at the level of cognitive technologies;

- the technological nature of cognition procedures makes it possible to carry out strategic planning of scientific activities, to evaluate the realism of fantastic views, to foresee risks and to achieve the desired effect of scientific research and development;

- science as a system-forming link of the whole complex of NBIC-technologies forms the technological image of the whole sphere of production of goods and services.

The latter circumstance is extremely important for understanding the quality of sustainable development - progress or regress, the speed and nature of innovations, the scale of structural and dynamic changes.

\section{Results and Discussion}

So, if the current system of production, economic and social and ecological relations perceives the challenges of NBIC-technologies, receives real support in the form of demand and proposals from the production and economic environment and civil society, a harmonious sustainable development will start with the realization of environmental potential in the form of converged technologies. If this balance is broken, then the prospects for the development of NBIC-technologies will be depressing, regardless the scenario for their further development. They can go in isolation from the imperative of sustainable development. NBIC-technologies have enough internal motivation for this subject. However, having be- 
come a goal in themselves, they will lose environmental constraints. The results of scientific and experimental activities, irrespective of the needs for sustainable development, will lead to their universal human futility. The feasibility of the development of NBICtechnologies will be in doubt and in the case of weak public susceptibility of the synergy of social and economic and environmental effects. In this version, the converged technologies will not be able to develop due to contradictions with the motivational incentives contained in them.

It can be argued that NBIC-technologies are an objective reality, and not a product of virtual intellectual constructions. In the format of these technologies society receives a subtle instrument and at the same time a powerful impetus to its sustainable development.

Direction to the results of research and development achieved in the system of basic technologies becomes the vector of development of the economies for all countries. Thus, the list of Critical Technologies of the Russian Federation is approved by the President of the Russian Federation. It includes 34 critical technologies. In addition, eight directions for the development of science and technology in the Russian Federation have been approved, which also cover critical technologies. The Government of the Russian Federation also established a rule for the establishing, adjustment and implementation of priority areas for the development of science, technology and technics in the Russian Federation and a list of critical technologies of the Russian Federation. In other countries, critical technologies have become less used to manage the strategic development of the economy. For example, the United States, France, Japan and other countries, by the beginning of this century, gradually moved away from the idea of creating the list of critical technologies. The USA were the pioneers of building such lists. In the framework of the famous RAND Corp. even in the second half of the 1990s, the Institute of Critical Technologies preparing such lists was closed. There was an opinion that a large list of critical technologies needed for the economy sprayed budgetary funds, did not allow to concentrate resources on the latest breakthrough technologies. In addition, it restricted the initiative of scientists and engineers to choose future, challenging disputes, sometimes "futuristic" trends of technological development at this stage. In addition, in the XXI century science is changing so rapidly that the choice of specific priority technologies can serve as a certain deterrent.

At the same time, no matter what the attitude to critical technologies was, there is no doubt that they are significant for concretizing the choice of directions for development. The availability of the list of critical technologies is especially important for the Russian economy, where, against the background of terminological confusion in terms of priority areas and national priorities, the vector of scientific and technological development of the country for the foreseeable future has been worked out only in the draft version. It is necessary to start from something and, gradually enlarging (by means of generalization) the number of directions, to choose one of the following qualitative trends of scientific and technological development:

First, the progress in the field of NBIC-technologies with the subsequent access to a fundamentally new trajectory of sustainable development of the nation and the whole of mankind, with the provision of potential leadership positions of the most innovative countries;

Secondly, the elimination of the technological backwardness of the Russian economy and the consequent transition to a high-tech basis for the economic potential development. Such a quality of economic development is associated with a small gap from the world scientific and technological level and the possibility of accelerated development of certain NBIC technologies.

Whatever the objective function of sustainable development has been chosen as a priority, the list of critical technologies will be refined and brought into line with the tasks of scientific and technological development that are at the specific time. It is important that the 
list of critical technologies is not declarative, but is a real tool for managing science and technology.

It is obvious that the real assessment of the resource potential, the degree of progress of the scientific and technological directions, and the image of the country's economy in the medium and long term run should become the criteria for selecting qualitative parameters for economic development.

The revolution of NBIC-technologies, global challenges for sustainable development make changes in the traditional innovation policies and strategies in the developed countries all over the world. This was demonstrated with particular conviction by the global financial and economic crisis at the end of the first decade in the 21 st century. Mankind is not protected from subsequent global challenges and crises, such as energy, environmental, demographic and others, which are difficult to predict today. At the same time, the convergence and synergy of NBIC-technologies can largely support governments in overcoming and mitigating the global challenges and crises of the 21 st century, in particular changing the structure of the world trade, which will increasingly be saturated with innovative goods and services.

Another major trend of global development in the XXI century is the birth, at this stage, of various social structures or societies emerging as a result of the large-scale development of certain global technologies, which include NBIC-technologies. As a result of penetration of these technologies into the various political, social and economic and cultural subsystems of modern post-industrial civilization, the "information society", the "bio community", the "nano- society" and, in the long term, the "cognitive society", which in the world scientific literature is conceptually united under the general term "knowledge society», are being formed. However, convergence and synergy of NBIC-technologies will ultimately lead to social and economic, political and other types of convergence and synergy, forming a new "sustainable innovative society", and ultimately a stable and harmonious civilization of the 21 st century.

Started in the late XX - early XXI century the active process of innovation and technological convergence means not only mutual influence, but also interpenetration of technologies, when the boundaries between individual technologies are blurred, and the final results appear in the framework of interdisciplinary research at the intersection of various fields of science and technology. Technological convergence is clearly manifested at the intersection of technologies that are part of the "bundle" of NBIC- technologies, which represent the merging of various sciences and technologies into a single scientific and technological area of knowledge. Such a scientific field will include almost all levels of organization of substance: from the atomic-molecular nature (nano), to the nature of life (bio), the nature of mind (cogno), and the processes of information exchange in material structures (info). Apparently, as a result, a meta-area of knowledge may arise.

At the international political level, the concept of technology convergence was developed by experts from a number of industrialized countries that are members of the EU and G-8, as early as the beginning of the 21 st century. This concept is based on the materials of four conferences held in the USA (2001-2005) and reports of the European High Level Expert Group (HLEG).

In the US, these conferences were held under the auspices of the "National NanoInitiative" of the US President and the NSF, and in Europe - under the auspices of the EU. Based on the results of the discussions, the principle of the "synergetic combination of the four scientific and technological areas", developing at an exceptional rate, was taken as a basis for the concept of technological convergence:

1) Nano-science and nanotechnology.

2) Biotechnology and biomedicine, including genetic engineering. 
3) Information technologies, including the latest computer and communication technologies.

4) Cognitive sciences, covering neurosciences and cognitive technologies.

These areas have received the generally accepted and currently used in the world practice term "NBIC-science and NBIC-technologies". The technological convergence scheme was proposed in 2003 by American scientists M. Roco and U. Bainbridge from the National Science Foundation of the United States.

The development of NBIC-convergence forms a new living space for mankind, its new ecology. Atoms, molecules, information bits and neurons, which are fundamental elements of NBIC technologies, interact with each other in various ways in the process of convergence and synergy of these technologies. An important element in this conceptual system is the national and global policy of the industrialized countries, which accelerates or stagnates the development of NBIC technologies, and consequently, the entire process of the formation of the innovative economy of the 21 st century. In accordance with the vector of these processes, a new policy of environment protection and improving living conditions is being formed.

Thus, in the line of the European High Level Expert Group (HLEG), the focus in the development of the EU innovation policy is not on convergence areas but on specific R \& $\mathrm{D}$ areas that need to be implemented in order to move to the creation of converged technologies and, on their basis, to develop the corresponding marketable products by 2020-2030 years. This group has identified five main areas of research, in which the development of specific converged technologies and related devices and other promising innovative products are provided.

So, for example, the direction number 1 "Healthcare" includes the creation of the following objects that can massively change the habitat and lifestyle of people:

- technologies and so-called laboratories, mounted in chips for the purpose of conducting a quick scan of the health state and determining the diagnosis of the patient, including a patient remote from the medical facility;

- "smart prostheses", which are capable of responding to human brain signals and transmitting relevant sensory information back, and others.

Direction number 4 "Ecology" and direction number 5 "Power energy" include the development and creation of:

- new energy carriers and technologies for their storage, imitating natural systems;

- renewable energy sources, including photoelectric systems, hydrogen, geothermal and solar energy technologies;

- autonomous "smart homes" and "smart energy systems";

- biomimetic technologies that simulate natural processes and integrate photoelectric systems into "smart materials";

- environmental sensors, incorporated into the information and management systems.

It seems that the application of technologies in directions numbers 1-5 will have a generally positive impact on the environment. However, the high cost and inaccessibility of some equipment and technological innovative products for all members of society can, from the point of view of the principles of technological synergetic, cause certain social fluctuations and chaos in the society. The main emphasis in the innovation policy of industrialized countries is made on R \& D aimed at strengthening the neuro-systems and potential capabilities of the human brain, as well as on the development of cognitive and computer neuroscience, nano-medicine, artificial intelligence, nano-electronics, biomedicine, enhancing the physical capabilities of a human (for example, creating exoskeletons) and etc.

\section{Conclusion}


Analysis of global trends and forecasts of the EU and the US shows that at the moment some converged technologies from the group of NBIC-technologies are still at the embryonic stage of development. However, in the future until 2030, these technologies should take a leading position in the global innovation economy and become a priority for sustainable development of G-8 countries, as well as some countries in Asia. Convergence and synergy of NBIC-technologies will lead to the formation of new trends of the "green economy" - nano-economy, bio-economics, information economy, cognomics (economy using cognitive technologies). Under their influence, a transition to new forms of social development aimed at harmony of the interests of mankind and environmental protection is expected. Such a transition will be accompanied by a change in ecological culture, values in society, a new psychology of social development, the emergence of new moral and ethical norms, which is already taking place now. Synergy of NBIC-technologies has a direct or indirect impact on people's ecological thinking and their readiness to develop environmentally safe products, create demand for it in local and global markets. NBIC-technologies will affect the transformation of people's thinking, which may entail a change in the content and structure of modern civilization or lead to a transition from a post-industrial to a harmonious with nature society.

\section{References}

1. A.A. Khoreshok, L.E. Mametyev, A.Y. Borisov, A.V. Vorobyev, IOP Conf. Ser.: Mater. Sci. Eng., 127:1, 012039 (2016)

2. A.A. Khoreshok, L.E. Mametyev, A.Y. Borisov, A.V. Vorobyev, IOP Conf. Ser.: Mater. Sci. Eng., 127:1, 012014 (2016)

3. S.A. Zhironkin, Ugol', 6, 62-63 (2001)

4. S.A. Zhironkin, Ugol', 4, 47-49 (2002)

5. V. Trifonov, O. Loyko, D. Nesteruk, S. Zhironkin, E. Strekovtsova, AIP Conf. Proceed., 1800, 050009 (2017)

6. E.V. Kucherova, T.A. Ponkratova, T.A. Tyuleneva, N.A. Cherepanova, Economics and Innovation Management, 1, 76-89 (2017) DOI: 10.26730/2587-5574-2017-1-76-89

7. N.N. Golofastova, V.G. Mikhailov, I.V., Seredyuk I.V. Economics and Innovation Management, 1, 66-75 (2017) DOI: 10.26730/2587-5574-2017-1-66-75

8. A.V. Myaskov, A.S. Ilyin, S.M. Popov, Gornyi Zhurnal, 2, 51-56 (2017)

9. O. Erdem, T. Güyagüler, N. Demirel, J. Sout. Afr. Inst. Min. Met., 112:5, 405-412 (2012)

10. S. Zhironkin, M. Gasanov, G. Barysheva, K. Kolotov, O. Zhironkina, E3S Web of Conf., 15, 03012 (2017)

11. A. Balabanova, V. Balabanov, E. Dotsenko, N. Ezdina, E3S Web of Conf., 15, 04013 (2017)

12. S.A. Zhironkin, K.A. Kolotov, O.V. Zhironkina, Economics and Innovation Management, 1, 4-16 (2017) DOI: 10.26730/2587-5574-2017-1-4-16

13. Z. Jurkasová, M. Cehlár, S. Khouri, Int. Conf. on Engin. Sci. and Prod. Man., ESPM, 409-412 (2015) 